\title{
Computer evaluation of reference curves for the estimation of extrinsic coagulation factors
}

Citation for published version (APA):

Frank, H. L. L., Dreessen, V., \& Hemker, H. C. (1978). Computer evaluation of reference curves for the estimation of extrinsic coagulation factors. Computers in Biology and Medicine, 8(1), 65-70. https://doi.org/10.1016/0010-4825(78)90014-8

Document status and date:

Published: 01/01/1978

DOI:

10.1016/0010-4825(78)90014-8

Document Version:

Publisher's PDF, also known as Version of record

\section{Please check the document version of this publication:}

- A submitted manuscript is the version of the article upon submission and before peer-review. There can be important differences between the submitted version and the official published version of record.

People interested in the research are advised to contact the author for the final version of the publication, or visit the DOI to the publisher's website.

- The final author version and the galley proof are versions of the publication after peer review.

- The final published version features the final layout of the paper including the volume, issue and page numbers.

Link to publication

\footnotetext{
General rights rights.

- You may freely distribute the URL identifying the publication in the public portal. please follow below link for the End User Agreement:

www.umlib.nl/taverne-license

Take down policy

If you believe that this document breaches copyright please contact us at:

repository@maastrichtuniversity.nl

providing details and we will investigate your claim.
}

Copyright and moral rights for the publications made accessible in the public portal are retained by the authors and/or other copyright owners and it is a condition of accessing publications that users recognise and abide by the legal requirements associated with these

- Users may download and print one copy of any publication from the public portal for the purpose of private study or research.

- You may not further distribute the material or use it for any profit-making activity or commercial gain

If the publication is distributed under the terms of Article $25 \mathrm{fa}$ of the Dutch Copyright Act, indicated by the "Taverne" license above, 


\title{
COMPUTER EVALUATION OF REFERENCE CURVES FOR THE ESTIMATION OF EXTRINSIC COAGULATION FACTORS
}

\author{
H. L. L. Frank, * V. Dreessen and H. C. HeMker \\ Department of Biochemistry, Biomedical Centre, State University Limburg, Maastricht, \\ The Netherlands
}

(Received 2 December 1976)

\begin{abstract}
A program is described that, when fed the clotting times obtained by a given reagent with a series of known clotting factor concentration, gives the chemical constants of the reagent system and a table from which the clotting factor concentration in an unknown sample can be read from the clotting time obtained with that sample.
\end{abstract}

Clotting time Clotting factor (concentration of) Reference curve Blood coagulation Clinical pathology

\section{INTRODUCTION}

Estimation of a coagulation factor resembles a pharmacological bioassay more closely than a chemical determination: Some agent (the coagulation factor) produces an effect (coagulation) that can be quantitated (coagulation time). In a series of concentrations (dilutions) of normal plasma an empirical relation between dose and effect is determined without consideration of the underlying mechanism. The effect of the agent present in an unknown sample is then assessed and compared to the effects of the known samples. From this comparison the concentration in the sample is inferred. Most often this is carried out by means of the double logarithmic reference curve. The use of a double logarithmic representation is a purely practical one: often such a curve is indistinguishable from a straight line, which is very convenient for the manual elaboration of the graphs.

In a chemical determination and therefore also in an enzymological one, the base of the determination is a known reaction mechanism. From the reaction mechanism the type of relation between the concentration of a reactant and the phenomenon measured (either a reaction velocity or the concentration of a product) is known. Therefore, the type of function relating the unknown concentration to the effect measured is known. In simple titrations e.g. this is a simple proportionality. In simple enzymatic reactions it is given by the Briggs-Haldane formula [1]. This markedly restricts the degrees of freedom of the cause-effect curve. Aberrations from this curve can be interpreted as random error, and statistical methods can be applied accordingly.

In coagulation, this difference between chemical and pharmacological estimations has not always been sufficiently realised. A coagulation assay sufficiently resembles a chemical determination to make the investigator believe that the double logarithmic representation must hold, as if it were resulting from a chemical law.

The literature provides ample examples of the mistakes due to this attitude, and every day practice in the coagulation laboratory provides even more. The most serious mistakes are

(a) points deviating from a straight line on a $\log -\log$ reference curve are neglected.

(b) points deviating from a straight line on a log-log reference curve are thought to deviate by random error.

(c) the rectilinear $\log -\log$ reference curve is extended beyond the points tested experimentally.

* Department of Cardiology, Hospital St. Annadal, Maastricht, The Netherlands. 


\section{THE RELATION BETWEEN CLOTTING TIME AND CLOTTING FACTOR CONCENTRATIONS}

In a series of articles [2-6] we have shown that the reaction mechanism of extrinsic blood coagulation (i.e. involving the factors II, V, VII and X) as it is generally accepted on basis of experiments in a purified system is compatible with the kinetics of an unpurified system. In experiments in which the experimental error was reduced by carrying out estimations in several hundred fold it was shown that for each of the factors of the extrinsic system (i.e. factors II, V, VII, and X) the relation between the concentration of the rate limiting factor and the coagulation time is of the type:

$$
t_{c}=t_{\min }+\frac{1}{c_{\mathrm{tot}}} \cdot \underline{a}
$$

where $t_{c}=$ coagulation time, $t_{\min }=$ coagulation time at infinite concentration of the rate limiting coagulation factor, $c_{\mathrm{tot}}=$ the total concentration of the rate limiting factor and $\underline{a}=t_{\min } \cdot K_{m} ; k_{m}$ being the concentration of the rate limiting factor at which twice minimal coagulation time is observed. In this set $c_{\text {tot }}$ is the independent variable, $t_{c}$ is the dependent variable and $t_{\min }$ and $\underline{a}$ are constants for a given system of estimation.

The reaction mixture in which this relation has been proven to exist consists of $0.1 \mathrm{ml}$ of reagent, i.e. of plasma deficient in the factor to be tested containing all other factors in a fixed high concentration

$0.1 \mathrm{ml}$ of a dilution of normal plasma c.q. sample

$0.1 \mathrm{ml}$ of thromboplastin

$0.1 \mathrm{ml}$ of $\mathrm{CaCl}_{2}, 1 / 30$ or $1 / 40 \mathrm{M}$.

Complete details on reagents etc. are to be found in Ref. [7].

In such a mixture the concentration of the rate limiting coagulation factor is the sum of two concentration: (a), that added with the normal plasma or the sample $C_{\text {ad }}$, and (b), that added with the reagent $C_{r}$.

In the ideal reagent $C_{r}$ is zero, it hardly ever is because reagents completely deficient in a given factor are hard to obtain in practice. Recently, a factor II reagent with $C_{r}=0$ has been described, though [8]. Taking into account the double source of $C_{\text {tot }}$, formula 1 becomes

$$
t_{c}=t_{\min }+\frac{1}{C_{\mathrm{ad}}+C_{r}} \cdot t_{\min } K_{m}
$$

$C_{\text {ad }}$ is the independent variable, $t_{c}$ is the dependent variable and $C_{r}$ is another constant (in a given system).

When in a given system for a series of $C_{\text {ad }}, t_{c}$ is measured, the constants $t_{\min }, K_{m}$ and $C_{r}$ can be calculated. It is the advantage of this type of approach that deviations of $t_{c}$ are now justified to be regarded as random error or experimental drop-outs (see paragraph on experimental errors).

Once $t_{\min }, K_{m}$ and $C_{r}$ are known, formula (2) can be used to calculate $C_{a d}$ from any value of $t_{c}$ found experimentally, the formula being:

$$
C_{\mathrm{ad}}=\frac{K_{m}}{\frac{t_{c}}{t_{\min }}-1}-C_{r}
$$

This formula is too complicated to be used as such in the daily practice of the laboratory; therefore a reference table is printed in which $C_{\text {ad }}$ belonging to a useful series of $t_{c}$ can be read.

The program was developed on a PDP-12 computer, programmed in FOCAL-12 $(8 \mathrm{~K})$ and then transcribed and tested in FORTRAN-4 on an IBM $1800(32 \mathrm{~K})$ and in ALGOL-60 on a X-8. 


\section{THE ERROR IN COAGULATION TIME ESTIMATION}

As can be judged from Table 1, the error in a coagulation factor assay is almost independent of the coagulation time when expressed as a percentage of that time. This means that long coagulation times show bigger absolute errors than small ones. Therefore, points in the higher concentration range have to be weighed more heavily when a curve is fitted through a series of $t_{c}-C_{\mathrm{ad}}$ points.

From Table 1 it can also be seen that the error in a coagulation time determination drops appreciably with experience. The error of an individual coagulation time determination is seen to improve from 8 to $\mathrm{ca}$. $6 \%$.

A further peculiarity of the errors in coagulation time determinations is that it is relatively often observed that individual points of a $C_{\mathrm{ad}}-t_{c}$ set drop out more than three standard deviations from the line that can be fitted through the rest of the points. It is justified to discard these points, because the change of these deviations being due to random error in the determination is less than $1 \%$.

Table 1. Clotting times at different clotting factor concentrations

\begin{tabular}{lcccccc}
\hline$C_{a d}(\%)$ & $t_{c}(\mathrm{sec})$ & S.D. $(\mathrm{sec})$ & S.D. $(\%)$ & $t_{c}(\mathrm{sec})$ & S.D. $(\mathrm{sec})$ & S.D. $(\%)$ \\
\hline 10 & 25.0 & 1.6 & 6.4 & 25.5 & 2.2 & 8.6 \\
5 & 29.5 & 2.0 & 6.8 & 32.3 & 2.2 & 6.8 \\
2.5 & 35.1 & 2.3 & 6.6 & 38.0 & 3.1 & 8.2 \\
1.67 & 40.8 & 2.4 & 5.9 & 44.6 & 2.9 & 6.5 \\
1.25 & 45.3 & 2.6 & 5.7 & 47.1 & 3.3 & 7.1 \\
1 & 47.9 & 3.2 & 6.7 & 50.3 & 5.0 & 10.0 \\
0 & 72.7 & 3.3 & 4.5 & 72.5 & 6.6 & 9.1 \\
mean & & & 6.1 & & & 8.0 \\
\hline
\end{tabular}

The figures give the mean and standard deviations of 30 individual estimations expressed as seconds or as percentage of the mean as obtained by two experienced technicians (A) and an unexperienced one (B).

The cause for these drop-outs is obscure, probably they are related to errors in preparations of the dilutions, unclear glassware etc. In the program therefore a procedure was built in to discard these points. This serves as an independent means of control for the consistency of the method. When systematically points in a defined range of concentrations in a series of reference curves happen to be discarded, the deviation must be due to a systematic error. This error has to be explained then c.q. the method has to be judged not applicable. When the drop-outs are random this means that the

\section{THE COMPUTER PROGRAM}

The computer program makes a three parameter fit of formula (2) to the $C_{\text {ad }}, t_{c}$ data pairs.

This is carried out by making a two parameter fit at different assumed values of $C_{r}$ until that $C_{r}$ is found at which the best fit is obtained. The fitting of a straight line at a given $C_{r}$ is carried out by calculating the minimum of

$$
D=\sum_{n=1}^{k} \sqrt{\frac{\left(C_{k}-Y_{k}\right)^{2}}{Y_{k}}}
$$

where $C_{k}=a x_{k}+b$ and $a$ and $b$ are the two parameters to be found. This minimum $(D)$ is a function of $C_{r}$. The value for $C_{r}$ for which $D$ in its turn reaches a minimum is the third parameter. Flowchart 1 shows how this is found. Formula (4) causes a weighing of the data points inversely proportional to $Y_{k}$. This is because the experimental error is proportional to $Y_{k}$ (see above). When the three parameters are obtained the pooled standard error $(P)$ is estimated from the sum of least squares used to fit the line. Any points deviating more than three times the S.D. from their theoretical counter- 


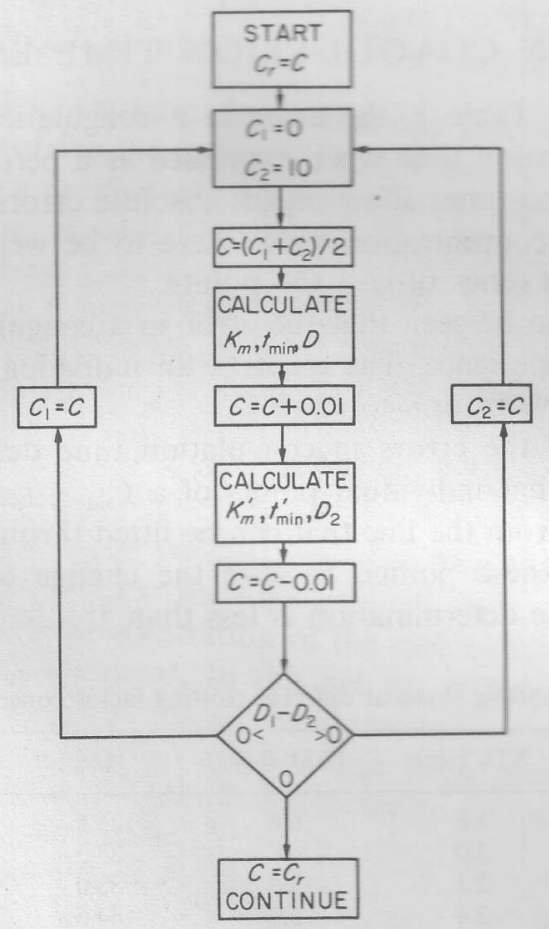

Fig. 1.

parts on the line obtained are discarded and the procedure is repeated. Thus a new $C_{r}, t_{\min }, K_{m}$ and $P$ are found. Anyone of the discarded points that with these new values falls within three times the S.D. is taken back in the set of used points and, the case being, the procedure is repeated again.

Table 2 shows an example of the input. Table 3 shows the output of the constants and statistical parameters calculated. The Table relating clotting times to concentrations is shown as Table 4.

Table 2. The input

\begin{tabular}{lc}
\hline Concentration & Clotting time \\
\hline $10.00 \%$ & $25.0 \mathrm{sec}$ \\
5.00 & 29.5 \\
2.50 & 35.1 \\
1.67 & 40.8 \\
1.25 & 45.3 \\
1.00 & 47.9 \\
\hline Reagent factor & 2 \\
Batch No. & 202 \\
Normal plasma No. & 1 \\
Thromboplastin No. & 602 \\
Ca-Chloride & $1 / 30 \mathrm{molair}$ \\
Buffer time & $72.7 \mathrm{sec}$ \\
Number of points & 6 \\
\hline
\end{tabular}

Table 3. Output I, the constants calculated from the data in Table 1

\begin{tabular}{lcc}
\hline & A & B \\
\hline Standard deviation & $0.48 \%$ & $0.88 \%$ \\
Factor in reagent & $0.81 \%$ & $0.95 \%$ \\
Minimum time & $20.46 \mathrm{sec}$ & $20.75 \mathrm{sec}$ \\
$K_{m}$ & $2.46 \%$ & $2.46 \%$ \\
\hline
\end{tabular}

Sub $\mathrm{B}$ are added the calculations obtained with the clotting times from colum B in Table 1. 
Table 4. Output II, the reference table

\begin{tabular}{|c|c|c|c|c|c|}
\hline \multirow[t]{2}{*}{ Clotting time (sec) } & \multicolumn{5}{|c|}{ Concentration $(\%)$} \\
\hline & 0.0 & 0.2 & 0.4 & 0.6 & 0.8 \\
\hline 25 & 10.28 & 9.81 & 9.38 & 8.99 & 8.62 \\
\hline 26 & 8.28 & 7.96 & 7.67 & 7.39 & 7.13 \\
\hline 27 & 6.89 & 6.66 & 6.45 & 6.24 & 6.05 \\
\hline 28 & 5.87 & 5.70 & 5.53 & 5.38 & 5.23 \\
\hline 29 & 5.09 & 4.95 & 4.82 & 4.70 & 4.58 \\
\hline 30 & 4.47 & 4.36 & 4.26 & 4.16 & 4.06 \\
\hline 31 & 3.97 & 3.88 & 3.79 & 3.71 & 3.63 \\
\hline 32 & 3.56 & 3.48 & 3.41 & 3.34 & 3.27 \\
\hline 46 & 1.16 & 1.15 & 1.13 & 1.12 & 1.10 \\
\hline 47 & 1.09 & 1.08 & 1.06 & 1.05 & 1.03 \\
\hline
\end{tabular}

The program is available in an English or French version, in either of the programming languages FOCAL-12, FORTRAN-4 or ALGOL-60 at cost price from the authors.

\section{PRACTICAL CONSEQUENCES}

In Table 3 the results are shown obtained with the program being applied to the data of Table 1. It is seen that the difference in experimental error readily shows up. It is also seen that where accurate determinations are needed, each investigator should use only his own reference table. This is because the moment of clotting is an arbitrary point, subject to individual differences between different workers.

In its calculations, the computer program does not use the buffer time. With the data from the program, the concentration of coagulation factor responsible for the buffer time can be calculated. When this concentration is compared to $C_{r}$ found by the program, they are equal to within $14 \%$. This has been observed in a series of 22 estimations of each of the factors II, V, VII, and X, tested with $10-1 \%$ of normal plasma. This can be considered a reasonable proof that the method is valid for all concentrations below $10 \%$, i.e. also for these below $1 \%$. This has been corroborated by observations on a completely deficient reagent reported elsewhere [8].

At high concentrations (above $15 \%$ ) of the normal plasma the method no longer applies. This is probably due to the high amounts of the other factors added with the sample in these cases. This problem is further investigated.

\section{SUMMARY}

Clotting factors are estimated by comparing clotting times $\left(t_{c}\right)$ obtained with unknown samples to clotting times obtained with samples of known concentration $(C)$. From fundamental work the type of the relation between $t_{c}$ and $C$ is known to be

$$
t_{c}=t_{\min } \cdot K_{m} /\left(C+C_{r}\right)+t_{\min } .
$$

(see text for explanation of the symbols).

As basis of this formula a program is developed that determines $t_{\min } \cdot K_{m} \cdot C_{r}$, (constant for a given reagent) and that prints a table from which the concentration belonging to a clotting time observed with an unknown sample can be read.

It is discussed why this approach is to be preferred to the usual $\log -\log$ reference curves. The types of errors occurring in coagulation factor determinations are discussed.

\section{REFERENCES}

1. M. Dixon and E. C. Webb, The Enzymes, Longmans, London (1964).

2. H. C. Hemker, P. W. Hemker and E. A. Loeliger, Thromb. Diathes. haemorrh. 13, 155-175 (1965).

3. H. C. Hemker, T. Siepel, R. Altman and E. A. Loeliger, Thromb. Diathes. haemorrh. 17, 350-357 (1967).

4. H. C. Hemker and A. D. Muller, Thromb. Diathes, haemorrh. 20, 78-87 (1968).

5. H. C. Hemker, C. Vermeer and J. Govers-Riemslag, Thromb. Haem., in press (1976).

6. H. C. Hemker and P. W. Hemker, Proc. Roy. Soc. B. 173, 411- 420 (1969).

7. H. C. Hemker, A. C. W. Swart and A. M. J. Alink, Thromb. Diathes. haemorrh. 27, 205-212 (1972).

8. C. Vermeer, B. A. M. Soute and H. C. Hemker, Thrombosis Res., in press (1976). 
About the Author-H. L. L. FRANK is a cardiologist in the Hospital of Maastricht, The Netherlands. His training as a cardiologist he got at Leyden University at the Department of Prof. H. A. Snellen. His Ph.D. degree he obtained on a thesis named "The effect of glycerol on the isolated perfused rat heart" prepared in the laboratory of the third author. One of his main interests is bridging the gap between the daily practice of cardiology and the achievements of basic research.

About the Author-V. DREESSEN finished the College of Advanced Techniques with electrotechnics as main branche. He worked during four years at the Dutch State Mines at Geleen, The Netherlands, as a system programmer. During the last three years he workes in the Department of Biophysics at the State University Limburg as a system programmer.

About the Author-H. C. HEMKER is professor of biochemistry at the State University Limburg, Maastricht, The Netherlands. His main research is the biochemistry of blood coagulation. 